\title{
Two oat genotypes with different field resistance to Fusarium head blight respond similarly to the infection at spikelet level
}

\author{
Juho Hautsalo ${ }^{1}$ (i) $\cdot$ Satu Latvala ${ }^{2} \cdot$ Outi Manninen $^{3} \cdot$ Minna Haapalainen $^{4} \cdot$ Asko Hannukkala $^{2,4} \cdot$ Marja Jalli $^{2}$
}

Received: 8 November 2019 /Revised: 14 September 2020 / Accepted: 18 September 2020 / Published online: 1 October 2020

(C) The Author(s) 2020

\begin{abstract}
Cultivar resistance is essential for the management of Fusarium head blight (FHB) disease in oat production. However, the breeders lack methods suitable for phenotyping disease resistance and resistance sources. In this paper we compared two oat genotypes, a rejected variety BOR31 and a landrace VIR7766, with four different traits that could reflect resistance to FHB in a greenhouse environment. Spray and point inoculations were used to inoculate Fusarium graminearum into flowering oat plants. When spray-inoculated, VIR7766 was significantly more resistant against the initial infection than BOR31, measured by the number of Fusarium-infected kernels and by DON accumulation. In the point-inoculated oats, the loss of fresh weight in the inoculated spikelet correlated well with the increasing F. graminearum biomass in the spikelet, measured six days after inoculation. However, no difference in the growth of the fungus was observed between the tested oat genotypes by point inoculation. We speculate that once the infection is established, the ability of the oat plant to resist the spread of the infection within a spikelet is low in the genotypes studied, although oat, in general, due to its panicle structure, is considered to have a high resistance against Fusarium infection.
\end{abstract}

Keywords Disease resistance $\cdot$ Panicle $\cdot$ Quantitative PCR $\cdot$ Resistance components $\cdot$ Screening methods

Oat (Avena sativa L.) has become increasingly popular for human consumption due to its health beneficial traits (EFSA 2009 and 2011). However, decreased seed quality due to Fusarium head blight (FHB) infections has led to rejections and market value reductions. Infection can reduce grain yield and especially its quality when mycotoxins accumulate in the grains, or germination capacity collapses (Bjørnstad and

Electronic supplementary material The online version of this article (https://doi.org/10.1007/s42161-020-00670-8) contains supplementary material, which is available to authorized users.

Asko Hannukkala is deceased on 10 May 2020.

Juho Hautsalo

juho.hautsalo@luke.fi

1 Natural Resources Institute Finland, Survontie 9A, Jyväskylä FI-40500, Finland

2 Natural Resources Institute Finland, Tietotie 4, Jokioinen FI-31600, Finland

3 Boreal Plant Breeding Ltd, Myllytie 10, Jokioinen FI-31600, Finland

4 Department of Agricultural Sciences, University of Helsinki, Helsinki FI-00014, Finland
Skinnnes 2008; Tekle et al. 2013). The worst problems in oats are due to accumulation of mycotoxins, such as deoxynivalenol (DON), which inhibits protein synthesis and can cause symptoms both in humans and animals. Due to acute toxicity of DON, limits for its concentration in grain have been set by EU (European Commission 2006). Fusarium graminearum Schwabe is the most important DON producing species in the Nordic region (Hietaniemi et al. 2016; Hofgaard et al. 2016) and the most important causal agent of FHB worldwide (Trail 2009).

Management of FHB would benefit from resistant cultivars, since when severe disease incidence occurs, FHB cannot be fully controlled in oats by agricultural or manufacturing practises (Hietaniemi 2016). Less susceptible genotypes have been identified in recent research (Tekle et al. 2018, Bjørnstadt et al. 2017, Gagkaeva et al. 2013), but the mechanisms behind the resistance are quantitative (He et al. 2013) and based on minor genes. Oat resistance against FHB is typically evaluated by measuring mycotoxin accumulation or other Fusarium associated traits such as infection rate or germination capacity from either greenhouse grown, sprayinoculated plants (Tekle et al. 2012; Xue et al. 2014) or from spawn-inoculated field nurseries (Gagkaeva et al. 2013; Tekle 
et al. 2018). A third inoculation method, point inoculation, has been used for visual estimation of symptom spread in wheat (Zhu et al. 1999) and barley (Langevin et al. 2004), but this has not been shown to be valuable in oats, where the quantification of symptoms requires a strong control of environmental factors (Xue et al. 2014; Bjørnstad et al. 2017) and the symptoms are not found to spread across the panicle (Langevin et al. 2004) as they do in the spikes of wheat or barley.

The objective of this study was to use spray and point inoculation methods to investigate FHB resistance in two oat genotypes in a greenhouse. The number of Fusarium-infected kernels and DON accumulation were compared by spray inoculation experiments. Point inoculations were used to test whether it is possible to measure FHB resistance in oats by determining the $F$. graminearum biomass by real-time PCR or by measuring the damage as the loss of fresh weight shortly after anthesis.

Greenhouse-produced seed of a susceptible oat variety BOR31 (Boreal Plant Breeding Ltd., Finland) and a moderately resistant, brown-hulled, Chinese landrace VIR7766 [N.I. Vavilov All-Russian Institute of plant genetic resources (VIR), Russia] were sown in 2 litre pots containing fertilized peat (Kekkilä Taimimulta, Kekkilä Group, Finland) supplemented with sand, and fertilized weekly with liquid fertilizer (Yara Ferticare, $14 \% \mathrm{~N}-11 \% \mathrm{P}-25 \% \mathrm{~K}-2.4 \% \mathrm{MgO}+$ micronutrients, Yara International, Norway). Plants were grown at $18 \mathrm{C} / 15 \mathrm{C}$ (day/night). The light intensity was kept above $200 \mathrm{~W} / \mathrm{m}^{2} 16 \mathrm{~h}$ per day.

In a greenhouse, two separate spray inoculation and point inoculation experiments were conducted. Spray inoculation experiments had four pots with five plants per genotype and these were randomized within four replicates. The point inoculation experiments had five pots with one plant per pot. The plants were inoculated at anthesis (BBCH 65) with $200 \mathrm{ml}$ of inoculum sprayed per 100 plants or $10 \mu \mathrm{l}$ inserted within three spikelets per each plant (Fig. 1). The inoculum was prepared of the DON-producing $F$. graminearum isolate 05011 , obtained from a cereal field in Finland in 2005 (Kokkonen et al. 2010). The inoculum concentration was $2.4 \times 10^{5}$ conidia $/ \mathrm{ml}$ for the spray inoculation experiments and $0.5 \times 10^{5}$ conidia $/ \mathrm{ml}$ for the point inoculation experiments. To obtain uniform dispersion of the conidia, Tween-80 $(0.01 \%)$ was added to the point inoculation suspension. The control spikelets were "inoculated" with sterile water. For the spray-inoculated plants, mist irrigation was applied for $2 \mathrm{~h}$ before and from $6 \mathrm{~h}$ after inoculation for $14 \mathrm{~h}$, whereas for point inoculations the panicles were covered with translucent plastic bags for $48 \mathrm{~h}$ following the inoculation. After both kinds of inoculations the temperature was raised to $20 \mathrm{C} / 18 \mathrm{C}$ (day/night).

Main stems from each pot were harvested at $\mathrm{BBCH} 92$ from the spray inoculated experiments ( 5 panicles per sample, 4 replicate samples per experiment). Ten grains from each panicle were placed on selective pentachloronitrobenzene (PCNB) plates (Nash and Snyder medium, Nelson et al. 1983). Fusarium-infected kernels (FIK), showing bleaching and discolouration symptoms, were counted after one week incubation at $23{ }^{\circ} \mathrm{C}$ and shown as percentage of infected grains per replicate $(n=04$ per genotype per experiment, 16 in total). DON contents were analysed from milled grain samples $(n=16)$ with ELISA kit (R5906 Ridascreen DON 96 test, R-Biopharm, Darmstadt, Germany). Hyphal tip cultures on PDA plates were made from the PCBN plates in each experiment and checked with microscope to confirm the causal agent of the infection.

At six days post inoculation (dpi), the point-inoculated spikelets were separately harvested and stored at $-80{ }^{\circ} \mathrm{C}$. A total of 60 inoculated spikelets (three technical repeats from five plants in two experiments and two genotypes) and 20 water-inoculated spikelets (one per plant) were weighed and analysed by real-time PCR for $F$. graminearum biomass (Supplementary material). The fresh weight reduction was determined by comparing the weight of each of the $30 \mathrm{~F}$. graminearum-inoculated spikelets to the mean weight of the water-inoculated control spikelets

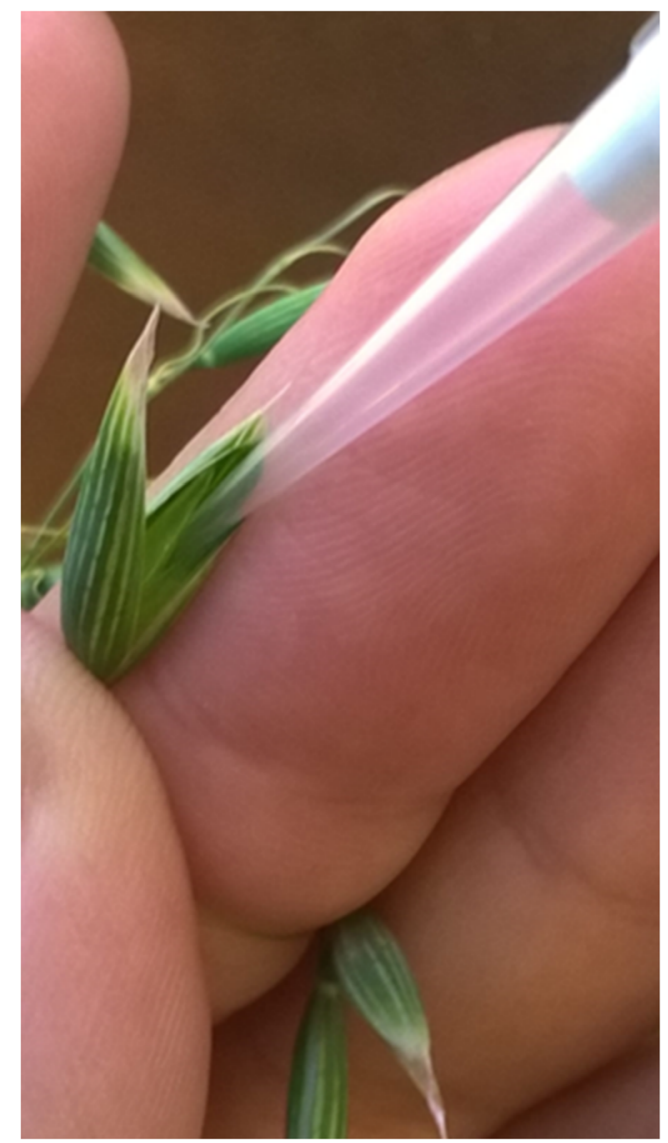

Fig. 1 In the point inoculations a droplet of $F$. graminearum inoculum was inserted between the palea and lemma of the primary oat floret. The outermost spikelets from the median part of the panicle were selected for the point inoculations 
per experiment (10 in the 1 st experiment and 30 in the 2nd experiment).

The landrace VIR7766 had significantly less infected kernels and DON accumulation than the rejected variety BOR31 (Table 1). This is in agreement with the two-year field resistance screenings (Gagkaeva et al. 2013) that rated the landrace, VIR7766, as a moderately resistant accession with multicomponent resistance, resisting both mycotoxin formation and spreading of infection from hulls to the seed. In addition, BOR31 has been found to be very susceptible to DON accumulation and Fusarium infections in several greenhouse experiments made in Natural Resources Institute Finland, Luke (Hautsalo et al. 2020, submitted). 'VIR7766' has also brown hull which is a trait that has been associated with FHB resistance in oats (Rainio 1932, Loskutov et al. 2016), although the impact of this trait could not be evaluated in this study. In addition to that VIR accessions can have other interesting mechanisms that may restrict the infection such as the higher level of wax production in cv. Argamak (VIR14648) (Willforss et al. 2020).

Point inoculation of oat spikelets with the inoculum suspension resulted in accumulation of $F$. graminearum biomass within the spikelets (Fig. 2), which was measured at 6 dpi by real-time PCR (Supplementary material). Mixed model statistical analysis (SAS Enterprise Guide 7.1, SAS Institute Inc., Cary, NC, USA) was performed with the $F$. graminearum/ plant DNA ratios normalized with log-transformation and genotype, experiments and their interaction set as fixed effect and replicates nested within experiments as random factors. The average $F$. graminearum/plant DNA ratio differed significantly $(\mathrm{p}<0.01)$ between the first and the second point inoculation experiment, with mean \pm S.D $92,500 \pm 153,000$ and $6700 \pm 4500$, respectively. The oat genotypes did not differ in their relative $F$. graminearum biomass $(\mathrm{p}=0.50)$. This was surprising, because several previous studies had shown that in Fusarium-infected oat the Fusarium DNA content and mycotoxin levels had a strong positive correlation in samples that were collected after ripening (Yli-Mattila et al. 2017; Gagkaeva et al. 2013; Fredlund et al. 2010) and the evidence suggested that 'VIR7766' could resist the spreading of infection into the grain (Gagkaeva et al. 2013). Moreover, in wheat and barley the resistant and susceptible genotypes can be

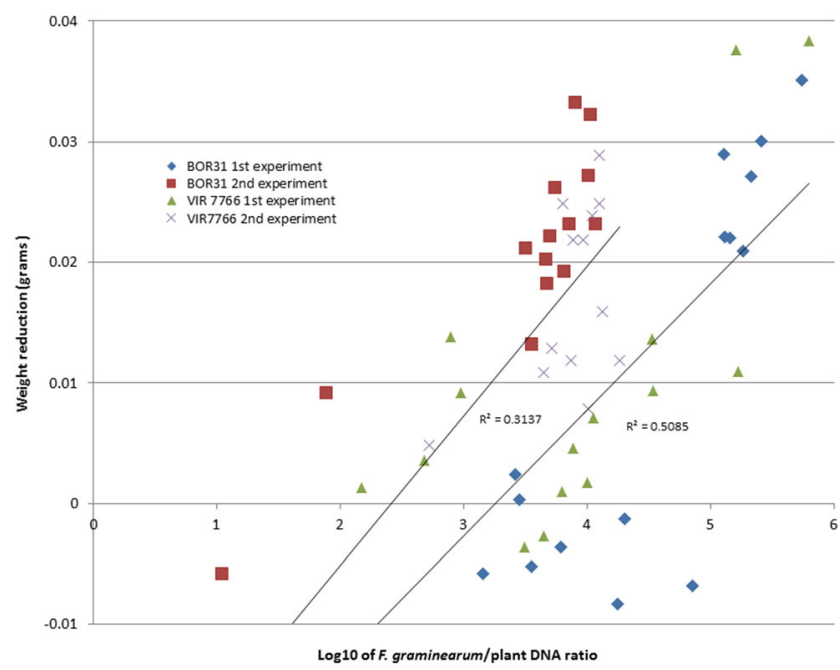

Fig. 2 Spikelet weight reduction showed statistically significant relation with the increase in $F$. graminearum biomass, determined six days after inoculation of the mid panicle region with Fusarium graminearum in two separate inoculation experiments. Results for the two different oat genotypes (VIR7766 and BOR31) in two different experiments (1st and 2nd) are represented by different point symbols

separated by $F$. graminearum biomass measurement after point inoculation by a similar method that was used in this study. The $F$. graminearum biomass results in wheat and barley correlated well with the visual estimations of spikelet and rachis resistance (Kumar et al. 2015; Kage et al. 2017). In a study on oats (Willforss et al. 2020), susceptible cv. Belinda and partially resistant $\mathrm{cv}$. Argamak were compared for DON accumulation at panicle level. The difference in DON accumulation between these genotypes was not found significant at $4 \mathrm{dpi}$, although the difference was significant in the samples taken at harvest. Similar approach where $F$. graminearum biomass would be measured at harvest could supplement our study.

Based on the results of this study, we suggest that the difference in DON accumulation between 'VIR7766' and 'BOR31' may largely result from type I resistance, the resistance against initial infection (Schroeder and Christensen 1963). It seems that the mycotoxin accumulation in these oats is a result of a series of individual infections occurring simultaneously within the panicles, since on average the FIK and DON results support each other (Table 1). These results are
Table 1 The estimates for accumulation of DON mycotoxin and percentage of

Fusarium-infected kernels and their standard errors from two separate spray inoculation greenhouse trials

\begin{tabular}{|c|c|c|}
\hline Oat genotype & DON accumulation, $\mu \mathrm{g} / \mathrm{kg}( \pm$ S.E. $)$ & Fusarium-infected kernels, $\%$ ( \pm S.E.) \\
\hline VIR7766 & $2735.8( \pm 178.6)$ & $25.0( \pm 6.2)$ \\
\hline BOR31 & $9966.2( \pm 178.6)$ & $91.5( \pm 6.2)$ \\
\hline Statistical analysis & $\mathrm{p}<0.05, \mathrm{df}=7, \mathrm{~F}=6.55$ & $\mathrm{p}<0.01, \mathrm{df}=7, \mathrm{~F}=113.49$ \\
\hline \multicolumn{3}{|c|}{$\begin{array}{l}\text { In the statistical analysis performed by SAS Enterprise Guide } 7.1 \text { (SAS Institute Inc., Cary, NC, USA) the DOI } \\
\text { values from spray inoculation experiments were normalized with square root transformation. In the analysis } \\
\text { DON accumulation or Fusarium-infected kernels, the model included genotype as fixed effect and the } \\
\text { experiments and replicates nested within experiments as random factors. }\end{array}$} \\
\hline
\end{tabular}


supported by the findings of Langevin et al. (2004) who described oats to be highly resistant against the spread of infection in panicle. Since our results did not point a mechanism that would differently restrain Fusarium infection in a spikelet of a moderately resistant oat compared to susceptible oat, it is likely that the panicle structure is an important restricting factor. Moreover, in our field studies the difference in FHB resistance between these two genotypes seems to fade away (Hautsalo et al. 2020), which also support this view. In field conditions, the type I resistance can be contributed by escape mechanisms, such as earliness, that are not observed in the greenhouse tests and weak agronomical traits can increase susceptibility of exotic genotypes.

The fresh weight reduction in the spikelets point-inoculated with $F$. graminearum in comparison with the water control was $0.012 \pm 0.015$ grams (mean \pm S.D., $p<0.001$ ) and according to similar statistical analysis as was performed for the $F$. graminearum biomass, it did not significantly differ between the oat genotypes nor the experiments (Fig. 2). $F$. graminearum infection had a similar effect on the spikelet weight in both inoculation events, despite the fact that the second experiment had less fungal biomass. This suggests that for the accumulation of $F$. graminearum biomass some destructive events within the infected plant tissue are required that release water from the tissue and thus reduce the fresh weight. This can actually be seen from the visible symptoms in the inoculated spikelets at 6 dpi (Fig. 3), although these were not quantified visually. F. graminearum is a hemibiotrophic fungus with a relatively short biotrophic phase of less than $48 \mathrm{~h}$ (Gottwald et al. 2012). The shift into the necrotrophic phase involves mycotoxin production and leads to oxidative reactions and cell death (Audenaert et al. 2014), which probably are the cause for the necrotic symptoms in the inoculated spikelet tissue. Similar observations were reported by Willforss et al. (2020). In the future, image analysis and high-throughput phenotyping approaches (Simko et al. 2017) could be applied in this kind of studies to measure the spreading of the infection.

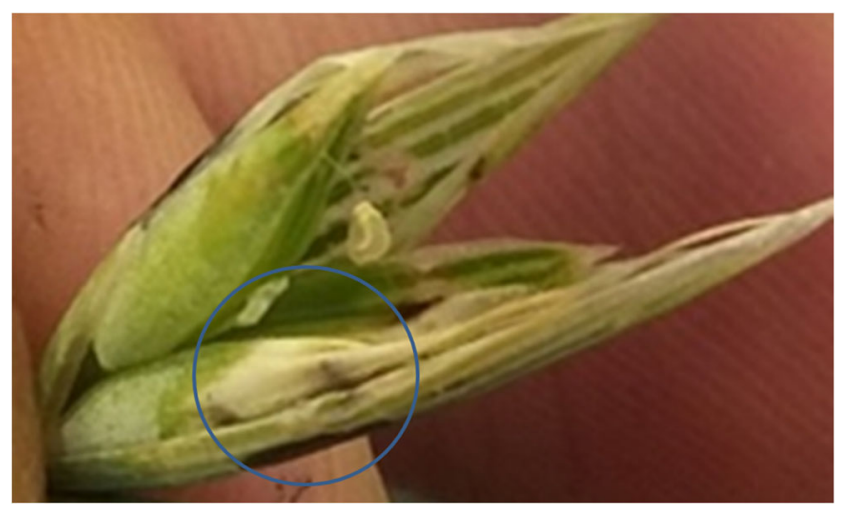

Fig. 3 Deterioration of plant tissue (loss of chlorophyll) in Fusarium graminearum-inoculated spikelets detected at $6 \mathrm{dpi}$. Deteriorating area is marked with a circle
The log-corrected $F$. graminearum/plant DNA ratio significantly $(\mathrm{p}<0.001)$ explained the weight reduction values in both the experiments $\left(R^{2}=0.51\right.$ in the 1 st experiment and $\mathrm{R}^{2}=0.31$ in the 2 nd experiment, Fig. 2). In spite of the significantly higher $F$. graminearum biomass in the 1st experiment, the spikelet weight reduction was similar in the two experiments. If differences in spikelet weight between genotypes would exist, this relationship between the spikelet weight reductions and the increase in $F$. graminearum biomass could provide a convenient and cost-effective method to quickly assess whether there is resistance against the spread of infection within the inoculated floral tissue. This is of interest for oats and also for other cereals, since symptoms and fungal biomass seem to correlate well (Kumar et al. 2015). Relative weight loss has been used in spray-inoculated resistance studies as a resistance parameter in wheat (Martin et al. 2017) and in oat (Martinelli et al. 2014), and it is shown to have a clear correlation with infection severity in both of these studies. However, weight reduction has not been studied at spikelet level in cereals before. Larger set of genotypes need to be studied to see the relevance of weight reduction method and more time points should be added to see if differences between genotypes are introduced later during the hostpathogen interaction, since the difference in $F$. graminearum biomass between the two separate point inoculation experiments (Fig. 2) suggests that the interaction continues after weight loss. Argamak and Belinda would be an interesting pair for this kind of study, since the proteogenomic background of their resistance has now been enlighten (Willforss et al. 2020). In addition, measuring DON accumulation in the point-inoculated spikelets and weight losses and/or $F$. graminearum biomass in the spray-inoculated panicles would increase our understanding of the nature of resistance and would thus be essential in the future studies.

Timing of inoculation to the right developmental stage is crucial in future inoculation studies, because after the anthesis the degrading anthers within the florets can act as a source of nutrients for the fungus (Tekle et al. 2012). On the other hand, if the inoculation is done too early, the plant tissue is less developed and softer, which can make the fungal penetration easier. Young tissue is often susceptible to infections with hemibiotrophic pathogens such as Colletotrichum (Peres et al. 2005). Because 'VIR7766' reached anthesis later than 'BOR31', the oat genotypes were point inoculated on different days with two weeks interval in the 1st experiment, which may have led to small environmental differences during the infection for the two genotypes. Therefore, the 2nd experiment was planted so that we were able to select and inoculate both genotypes at anthesis on the same day, which gave clearly less variable results for the $F$. graminearum biomass. Large deviations from the mean of the relative amounts of $F$. graminearum in plant and fresh weight reductions suggest 
that an adequate number of replications is also important for the reliability in point inoculations.

The point inoculations could also be used for testing the aggressiveness of different Fusarium isolates and comparisons of oat responses to these; since this method ensures that the spores of the fungus reach the susceptible inner parts of the floret. The contrasting responses of some oat genotypes to incidence of infected kernels, mycotoxin accumulation and germination capacity in inoculated field studies (Tekle et al. 2018, Hautsalo et al. 2020) suggest that the quantitative resistance in oats may be a combination of the effects of several (minor) factors and their interactions that are yet unknown to us. Considering that the resistance response of an oat genotype is a sum of several mechanisms acting simultaneously, methods for studying each of the contributing mechanisms separately are needed.

Acknowledgements Open access funding provided by Natural Resources Institute Finland (LUKE). The authors would like to acknowledge Aila Siren for her help with numerous point inoculations, Senja Tuominen for laborious real-time PCR analysis and the other Luke technicians Marjaana Virtanen, Päivi Koski, Anne Muotila and Auli Kedonperä for help with handling the grains, laboratory manager Kirsi Peltoniemi at Boreal Plant Breeding Ltd. for analysing DON contents and statistician Lauri Jauhiainen (Luke) for his advice with the data analysis.

Funding Following foundations are acknowledged for their financial support: Ministry of Agriculture and Forestry (Makera funding grant nr. 533/03.01.02/2018), Raisio Research Foundation, Tekes - the Finnish Funding Agency for Innovation, The Finnish Food Research Foundation and The Emil Aaltonen Foundation.

\section{Compliance with ethical standards}

Conflicts of interest Authors declare no conflict of interests.

Open Access This article is licensed under a Creative Commons Attribution 4.0 International License, which permits use, sharing, adaptation, distribution and reproduction in any medium or format, as long as you give appropriate credit to the original author(s) and the source, provide a link to the Creative Commons licence, and indicate if changes were made. The images or other third party material in this article are included in the article's Creative Commons licence, unless indicated otherwise in a credit line to the material. If material is not included in the article's Creative Commons licence and your intended use is not permitted by statutory regulation or exceeds the permitted use, you will need to obtain permission directly from the copyright holder. To view a copy of this licence, visit http://creativecommons.org/licenses/by/4.0/.

\section{References}

Audenaert K, Vanheule A, Höfte M, Haesaert G (2014) Deoxynivalenol: a major player in the multifaceted response of Fusarium to its environment. Toxins 6(1):1-19. https://doi.org/10.3390/toxins6010001

Bjørnstad Å, Skinnes H (2008) Resistance to Fusarium infection in oats (Avena sativa L.). Cereal Res Commun 36(6):57-62
Bjørnstad Å, He X, Tekle S, Klos K, Huang Y, Tinker NA, Skinnes H (2017) Genetic variation and associations involving fusarium head blight and deoxynivalenol accumulation in cultivated oat (Avena sativa L.). Plant Breed 13(65):620-636

European Commission (2006) Commission Regulation EC No 1881/ 2006 setting maximum levels of certain contaminants in foodstuffs Official. J Eur Union L364:5-24

European food safety author EFSA (2009) Scientific opinion on the substantiation of health claims related to beta-glucans and maintenance of normal blood cholesterol concentrations EFSA J 7:1254. https:// doi.org/10.2903/jefsa20091254/epdf

European food safety author EFSA (2011) Scientific opinion on the substantiation of health claims related to beta-glucans from oats and barley and maintenance of normal blood LDL-cholesterol concentrations ID 12361299 increase in satiety leading to a reduction in energy intake ID 851852 reduction of post-prandial glycaemic responses ID 821824 and "digestive function" ID 850 pursuant to Article 131 of Regulation EC No 1924/2006. EFSA J 9:2207. https://doi.org/10.2903/jefsa20112207/epdf

Fredlund E, Gidlund A, Pettersson H, Olsen M, Börjesson T (2010) Realtime PCR detection of fusarium species in swedish oats and correlation to T-2 and HT-2 toxin content. World Mycotoxin Journal 31: $77-88$

Gagkaeva T, Gavrilova O, Yli-Mattila T, Loskutov I (2013) Sources of resistance to fusarium head blight in VIR oat collection. Euphytica 1913:355-364. https://doi.org/10.1007/s10681-013-0865-7

Gottwald S, Samans B, Lück S, Friedt W (2012) Jasmonate and ethylene dependent defence gene expression and suppression of fungal virulence factors: two essential mechanisms of Fusarium head blight resistance in wheat? BMC Genom 2(13):369. https://doi.org/10. 1186/1471-2164-13-369

Hautsalo J, Jauhiainen L, Hannukkala A, Manninen O, Veteläinen M, Pietilä L, Peltoniemi K, Jalli M (2020) Resistance to Fusarium head blight in oats based on analyses of multiple field and greenhouse studies. Eur J Plant pathol. https://doi.org/10.1007/s10658-02002039

He X, Skinnes H, Oliver RE, Jackson EW, Bjørnstad A (2013) Linkage mapping and identification of QTL affecting deoxynivalenol DON content fusarium resistance in oats (Avena sativa L.). Theor Appl Genet 126(10):2655-2670. https://doi.org/10.1007/s00122-0132163-0

Hietaniemi V (2016) The fusarium mycotoxins in finnish cereal grains: How to control and manage the risk. Ph.D. Thesis. University of Turku

Hietaniemi V, Rämö S, Yli-Mattila T, Jestoi M, Peltonen S, Kartio M, Parikka P (2016) Updated survey of fusarium species and toxins in finnish cereal grains. Food Addit Contam Part A Chem Anal Control Expo Risk Assess 335:831-848

Hofgaard I, Aamot H, Torp T, Jestoi M, Lattanzio V, Klemsdal S, Brodal $\mathrm{G}$ (2016) Associations between fusarium species and mycotoxins in oats and spring wheat from farmers' fields in norway over a six-year period. World Mycotoxin J 93:365-378

Kage U, Karre S, Kushalappa AC, McCartney C (2017) Identification and characterization of a fusarium head blight resistance gene TaACT in wheat QTL-2DL. Plant Biotechnol J 15:447-457

Kokkonen M, Ojala L, Parikka P, Jestoi M (2010) Mycotoxin production of selected fusarium species at different culture conditions. Int J Food Microbiol 143:17-25

Kumar A, Karre S, Dhokane D, Kage U, Hukkeri S, Kushalappa AC (2015) Real-time quantitative PCR based method for the quantification of fungal biomass to discriminate quantitative resistance in barley and wheat genotypes to fusarium head blight. J Cereal Sci 64: $16-22$

Langevin F, Eudes F, Comeau A (2004) Effect of trichothecenes produced by fusarium graminearum during fusarium head blight development in six cereal species. Eur J Plant Pathol 1107:735-746 
Loskutov IG, Blinova EV, Gavrilova OP, Gagkaeva TY (2016) The valuable characteristics of oats genotypes and resistance to Fusarium disease. Russ J Genet Appl Res 7(3):290-298

Martin M, Schöneberg T, Vogelgsang S, Vincenti J, Bertossa M, MauchMani B, Mascher F (2017) Factors of wheat grain resistance to fusarium head blight. Phytopathol Mediterr 56:154-166

Martinelli JA, Chaves MS, Graichen FAS, Federizzi LC, Dresch LF (2014) Impact of fusarium head blight in reducing the weight of oat grains. J Agric Sci 65:188

Nelson PE, Toussoun TA, Marasas WFO (1983) Fusarium species: An illustrated manual for identification. The Pennsylvania State University Press, University Park, 193 pp

Peres NA, Timmer LW, Adaskaveg JE, Correll JC (2005) Lifestyles of colletotrichum acutatum. Plant Dis 898:784-796

Rainio AJ (1932) Punahome Fusarium roseum Link. gibberella saubinetii (Mont.) Sacc. ja sen aiheuttamat myrkytykset kaurassa. Valtion maatalouskoetoiminnan julkaisuja 50:45 p (In Finnish)

Schroeder HW, Christensen JJ (1963) Factors affecting resistance of wheat to scab caused by Gibberella zeae. Phytopathology 537(1): $831-838$

Simko I, Jimenez-Berni J, Sirault X (2017) Phenomic approaches and tools for phytopathologists. Phytopathology 107:6-17. https://doi. org/10.1094/PHYTO-02-16-0082-RVW

Tekle S, Dill-Macky R, Skinnes H, Tronsmo A, Bjørnstad A (2012) Infection process of Fusarium graminearum in oats (Avena sativa L.). Eur J Plant Pathol 1323:431-442
Tekle S, Skinnes H, Bjørnstad Å (2013) The germination problem of oat seed lots affected by fusarium head blight. Eur J Plant Pathol 1351: $147-158$

Tekle S, Lillemo M, Skinnes H, Reitan L, Buraas T, Bjørnstad Å (2018) Screening of oat accessions for fusarium head blight resistance using spawn-inoculated field experiments. Crop Sci 58(1):143-151. https://doi.org/10.2135/cropsci2017040264

Trail F (2009) For blighted waves of grain: Fusarium graminearum in postgenomics era. Plant Physiol 149:103-110

Willforss J, Leonova S, Tillander J, Andreasson E, Marttila S, Olsson O, Chawade A, Levander F (2020) Interactive proteogenomic exploration of response to Fusarium head blight in oat varieties with different resistance. J Proteomics. https://doi.org/10.1016/j.jprot.2020. 103688

Xue A, Chen Y, Marchand G, Guo W, Ren C, Savard M, McElroy ARB (2014) Timing of inoculation and fusarium species affect the severity of fusarium head blight on oat. Can J Plant Sci. 953. https://doi. org/10.4141/CJPS-2014-300

Yli-Mattila T, Rämö S, Hussien T, Rauvola M, Hietaniemi V, Kaitaranta J (2017) Different grain grinding methods affect detection of Fusarium graminearum DNA and mycotoxins. Phytopathol Mediterr 56:167-174

Zhu H, Gilchrist L, Hayes P, Kleinhofs A, Kudrna D, Liu Z, Prom L, Steffenson B, Toojinda T, Vivar H (1999) Does function follow form? Principal QTLs for Fusarium head blight FHB resistance are coincident with QTLs for inflorescence traits and plant height in a doubled-haploid population of barley. Theor Appl Genet 99: $1221-1232$ 